\title{
Measurements by controlled meteorological balloons in coastal areas of Antarctica
}

\author{
LARS R. HOLE ${ }^{1}$, ALEXIS PÉREZ BELLO ${ }^{2}$, TJARDA J. ROBERTS ${ }^{3}$, PAUL B. VOSS ${ }^{4}$ and TIMO VIHMA ${ }^{5}$ \\ ${ }^{1}$ Department of Oceanography and Marine Meteorology, Norwegian Meteorological Institute, Allegaten 70, 5007 Bergen, Norway \\ ${ }^{2}$ Department of Ocean and Atmospheric Physics, Institute of Meteorology of Cuba, La Habana, Cuba \\ ${ }^{3}$ LPC2E/CNRS, 3A, Avenue de la Recherche Scientifique, 45071 Orléans, Cedex 2, France \\ ${ }^{4}$ Picker Engineering Programme, Smith College, 100 Green Street, Northampton, 01063 MA, USA \\ ${ }_{5}^{5}$ Finnish Meteorological Institute, P.O. Box 503 FI-00101, Helsinki, Finland \\ lrh@met.no
}

\begin{abstract}
An experiment applying controlled meteorological (CMET) balloons near the coast of Dronning Maud Land, Antarctica, in January 2013 is described. Two balloons were airborne for 60 and 106 hours with trajectory lengths of $885.8 \mathrm{~km}$ and $2367.4 \mathrm{~km}$, respectively. The balloons carried out multiple controlled soundings on the atmospheric pressure, temperature and humidity up to $3.3 \mathrm{~km}$. Wind speed and direction were derived from the balloon drift. Observations were compared with radiosonde sounding profiles from the Halley Research Station, and applied in evaluating simulations carried out with the weather research and forecasting (WRF) mesoscale atmospheric model. The most interesting feature detected by the CMET balloons was a mesoscale anticyclone over the Weddell Sea and the coastal zone, which was reproduced by the WRF model with reduced intensity. The modelled wind speed was up to $10 \mathrm{~m} \mathrm{~s}^{-1}$ slower and the relative humidity was $20-40 \%$ higher than the observed values. However, over the study period the WRF results generally agreed with the observations. The results suggest that CMET balloons could be an interesting supplement to Antarctic atmospheric observations, particularly in the free troposphere.
\end{abstract}

Received 12 January 2016, accepted 21 April 2016, first published online 6 June 2016

Key words: Dronning Maud Land, observations, troposphere, WRF

\section{Introduction}

Observations on the Antarctic atmosphere are sparse and mostly limited to the lowermost few metres of the atmosphere. Near-surface air temperature (T), relative humidity (RH), wind speed (ws) and direction (wd), and atmospheric pressure $(\mathrm{P})$ are measured at manned and automated stations (Turner \& Pendlebury 2004). Other meteorological activities at manned stations include visual cloud observations (at practically all stations) and measurement of solar shortwave radiation (Pirazzini 2004), thermal longwave radiation (Walden et al. 1998) and turbulent fluxes of momentum and heat (Handorf et al. 1999), as well as atmospheric composition (Barbaro et al. 2015). However, at many stations measurements are only made during the summer. Most of the manned stations are located in coastal regions and there are large gaps between stations, especially in West Antarctica. Automatic weather stations provide important additional near-surface meteorological observations in Antarctica (Van den Broeke et al. 2004, Lazzara et al. 2012). Higher in the atmosphere, radiosonde soundings measure the vertical profiles of T, RH and wind up to $20-30 \mathrm{~km}$
(Durre et al. 2006). However, there are only about a dozen regularly operating sounding stations in Antarctica, most of them at coastal regions, and soundings are only made once or twice a day at most (Nygård et al. 2013). Over the Southern Ocean, the availability of in situ atmospheric observations is even more limited. In summer, a relatively small number of near-surface observations are made from ships, but only some of these utilize radiosondes. Marine meteorological observations have only been made during a few campaigns during the winter months (e.g. Andreas et al. 2002, Jonassen et al. 2015).

The available observations yield a basic understanding of weather and climate over Antarctica (King \& Turner 1997), and provide the necessary initial conditions for numerical weather prediction models (Bromwich et al. 2005). Increasing the spatial and temporal resolution of atmospheric observations is needed for several reasons. First, Antarctic weather forecasting would benefit substantially from additional observations of atmospheric $\mathrm{P}$ and vertical profiles of $\mathrm{T}, \mathrm{RH}$ and wind (Powers et al. 2012), with $\mathrm{P}$ and $\mathrm{T}$ observations being the most essential as initial conditions for operational 
a

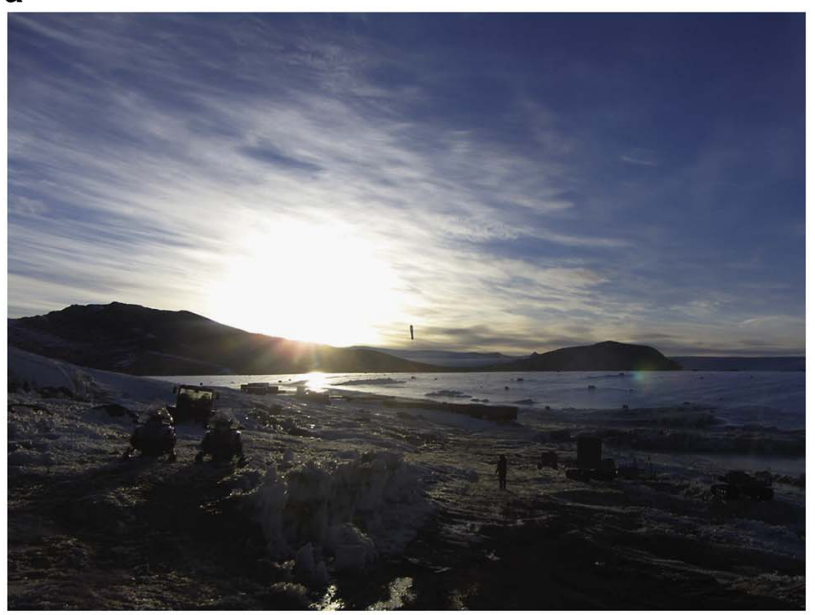

b

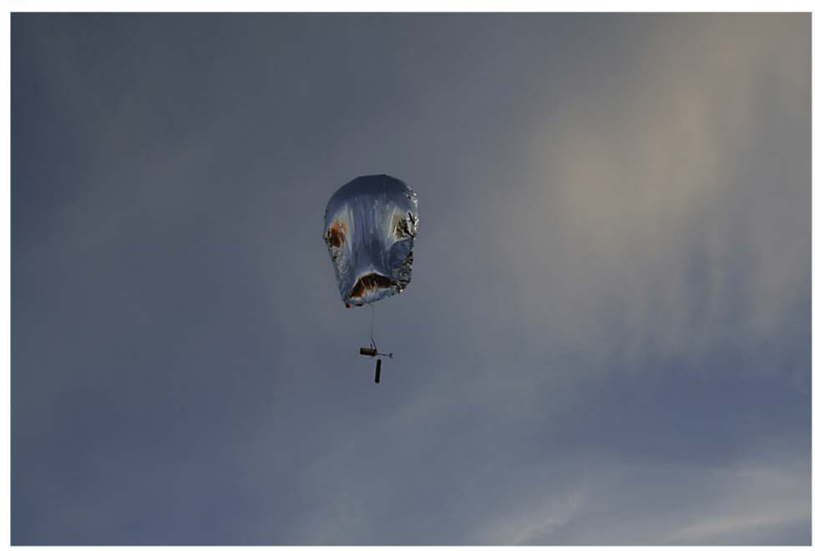

Fig. 1a. Controlled meteorological (CMET) balloon launched from Troll station, Antarctica, January 2012. b. CMET balloon just after launch. Photographs: P.B. Voss.

forecasting models. Second, more observations are needed to better evaluate the performance of numerical weather prediction and climate models in the Antarctic
(Tastula \& Vihma 2011). Identification of the model errors and the conditions when they occur is a prerequisite for model improvements. Third, more in situ atmospheric observations are needed to provide ground-truth data for validation and further improvement of satellite remote sensing algorithms. Fourth, better observational coverage is needed for several specific research areas addressing, among others, atmospheric dynamics, circumpolar heat, moisture and mass budgets, atmosphere-ocean and atmosphere-snow/ice interactions, as well as climate variability and change. Climatological studies in Antarctica are currently subject to considerable uncertainties due to the sparsity of observations (Bromwich et al. 2014).

Opportunities to increase the spatial and temporal coverage of in situ observations from the Antarctic atmosphere are relatively limited. Increasing the number of radiosonde stations and the frequency of soundings would improve weather forecasts and provide valuable data for process studies and climatological research, but the high costs and the infrastructure required mean that a large increase in sounding activity appears improbable. The recent development of unmanned aerial vehicles (UAV) shows promise (Cassano 2014, Knuth \& Cassano 2014, Jonassen et al. 2015) but the cost-effective operation of UAVs over large areas on a regular basis is still a major challenge. Hence, there is a need to identify new possibilities for cost-effective observation of the Antarctic atmosphere. As one possibility, we present data from a study in which two controlled meteorological (CMET) balloons (Voss et al. 2013, Stenmark et al. 2014) were launched near the coast of Dronning Maud Land in January 2013 (flying for 2.5 days and 4.5 days respectively). We show how the data can be used to evaluate simulations utilizing the weather research and forecasting (WRF) mesoscale atmospheric model (Skamarock et al. 2008).

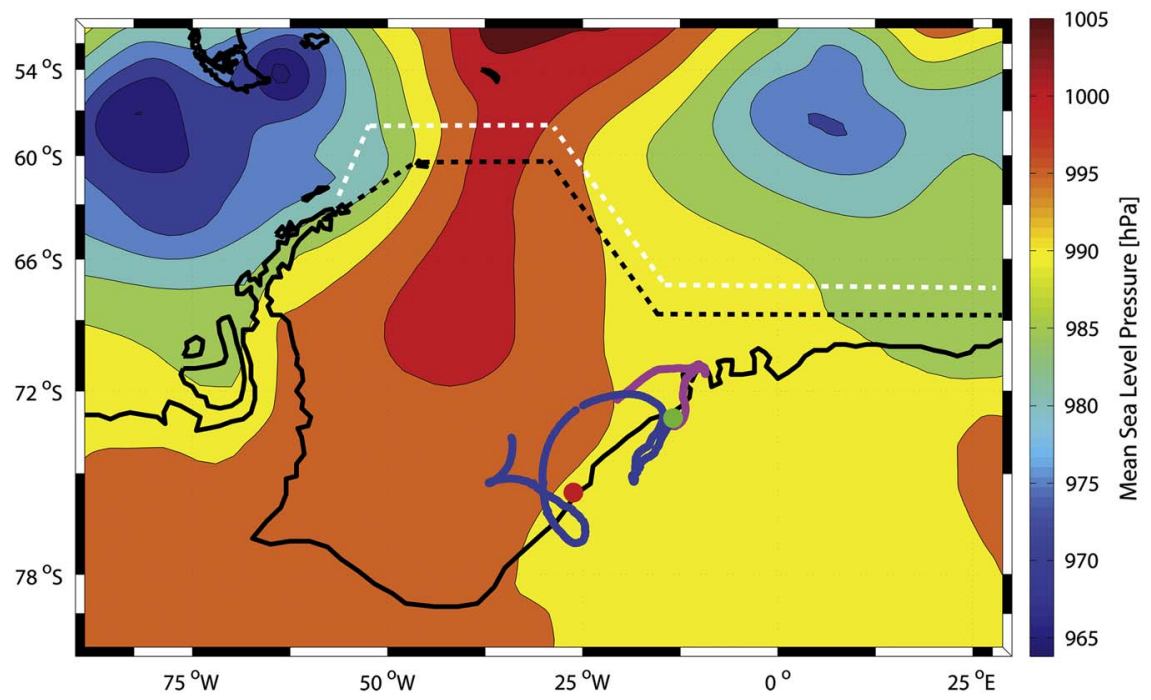

Fig. 2. Mean sea level pressure from the ERA Interim $80 \mathrm{~km}$ reanalysis (apps. ecmwf.int) for 19 January $201306 \mathrm{~h} 00$ UTC. The Alpha balloon trajectory is shown in magenta, while the Bravo balloon trajectory is shown in blue. The green dot is the location of the launch site at Aboa $\left(73.05^{\circ} \mathrm{S}, 13.41^{\circ} \mathrm{W}\right)$, while the red dot is Halley $\left(75.61^{\circ} \mathrm{S}, 26.18^{\circ} \mathrm{W}\right)$. The white dashed line is the approximate envelope of the January 2013 ice edge, while the black dashed line is the 19792012 median January ice edge provided by the National Snow and Ice Data Center (nsidc.org). 
Table I. Key characteristics of the controlled meteorological (CMET) balloon flights.

\begin{tabular}{llccr}
\hline & Launch date and time & End date and time & $\begin{array}{c}\text { Maximum altitude } \\
(\mathrm{m} \text { a.s.1.) }\end{array}$ & $\begin{array}{c}\text { Latitude range } \\
\left({ }^{\circ} \mathrm{S}\right)\end{array}$ \\
\hline Alpha & 16 Jan 2013 12h31 UTC & 19 Jan 2013 01h40 UTC & 3048 & $\begin{array}{c}\text { Longitude range } \\
\left({ }^{\circ} \mathrm{W}\right)\end{array}$ \\
Bravo & 18 Jan 2013 16h51 UTC & 23 Jan 2013 02h01 UTC & 3314 & 70.92 to 73.34 \\
\hline
\end{tabular}

\section{Observations}

\section{Controlled meteorological balloons}

Controlled meteorological balloons have been used previously in both the Arctic (Roberts et al. 2015) and Antarctic (Stenmark et al. 2014) (Fig. 1a). The payload weight is c. $250 \mathrm{~g}$ and the standard CMET balloon consists of an outer zero-pressure balloon (ambient pressure) and an inner super-pressure balloon (0-60 kPa above ambient) (Fig. 1b; Voss et al. 2013). To make the CMET balloon descend, a small diaphragm pump transfers helium from the zero-pressure balloon into the pressurized balloon, thus reducing the volume of the entire system and increasing its density. To ascend, the process is reversed using a small valve to release helium and inflate the zero-pressure balloon. The CMET balloon will then rise or fall until its overall density (including the payload mass) matches that of the surrounding atmosphere. The payload includes a GPS receiver and satellite modem for data transfer and in-flight balloon altitude control, and sensors for T, P and RH. The balloon is powered by a solar panel and a small lithium polymer battery (see Voss et al. 2013 for details).

On 16 and 18 January 2013, two CMET balloons, hereafter called Alpha and Bravo, were launched from the Finnish Aboa station in Dronning Maud Land $\left(73^{\circ} 03^{\prime} \mathrm{S}\right.$, $13^{\circ} 25^{\prime} \mathrm{W}$; Fig. 2). The balloons were airborne for $c$. 60 and 106 hours, respectively (Table I). A third balloon failed after a short flight because of overfilling with helium. On 21 January 2013 at 22h00 UTC, Bravo started to descend from c. $3200 \mathrm{~m}$ a.s.l., whilst at a horizontal distance of only $0.7 \mathrm{~km}$ from the British Halley Research Station, located on the Brunt Ice Shelf off the Caird Coast, Dronning Maud Land, at $75.61^{\circ} \mathrm{S} 26.18^{\circ} \mathrm{W}, 30 \mathrm{~m}$ a.s.l. (Fig. 2). On 22 January $00 h 00$ UTC, Bravo was at $378 \mathrm{~m}$ a.s.l. and $1 \mathrm{~km}$ from Halley. Consequently, this descent is well suited for comparisons with Halley radiosonde observations.

\section{Radiosonde data}

High-resolution radiosonde data from Halley for the study period were obtained from the British Antarctic Survey (BAS). The radiosondes are launched from Halley daily at $11 \mathrm{~h} 00$ UTC and with an ascent speed of $c .3 \mathrm{~m} \mathrm{~s}^{-1}$ they burst at $c .12 \mathrm{hPa} 30000 \mathrm{~m}$ a.s.l. after $c .150$ minutes. The standard radiosonde measurements include $\mathrm{P}, \mathrm{T}$ and $\mathrm{RH}$, with ws and wd derived from the flight. The vertical resolution of the radiosonde data is $10-11 \mathrm{~m}$.

\section{Model experiment}

The WRF model (Skamarock et al. 2008) version 3.5.1 was run in a three-domain set-up of 27,9 and $3 \mathrm{~km}$ resolution (not shown). The model was initialized on 16 January 2013 at 00h00 UTC and was run for 192 hours until 24 January $00 \mathrm{~h} 00$ UTC. The rapid radiative transfer model (RRTMG) (Iacono et al. 2008) was used for longwave and shortwave radiation schemes. The atmospheric surface layer was parametrized applying the Monin-Obukhov scheme, while the surface parametrization was based on a National Oceanic and Atmospheric Administration (NOAA) land-surface scheme operating with four layers including snow cover (Chen \& Dudhia 2001). For the planetary boundary layer, the Yonsei University (YSU) turbulence scheme was utilized (Hong et al. 2004). Lastly, the Kain-Fritsch scheme was used for the cumulus parametrization (Kain 2004), which allows for deep and shallow convection. The YSU turbulence scheme has previously proven to work well in Antarctica (Tastula et al. 2012, Stenmark et al. 2014). The initial and boundary conditions were taken from the NOAA global forecast system (GFS) with 0.5 degree resolution.

\section{Results}

The observation period was characterized by a large anticyclone building up east of the Antarctic Peninsula from 18 January 2013 (Bravo launch) (Fig. 2).
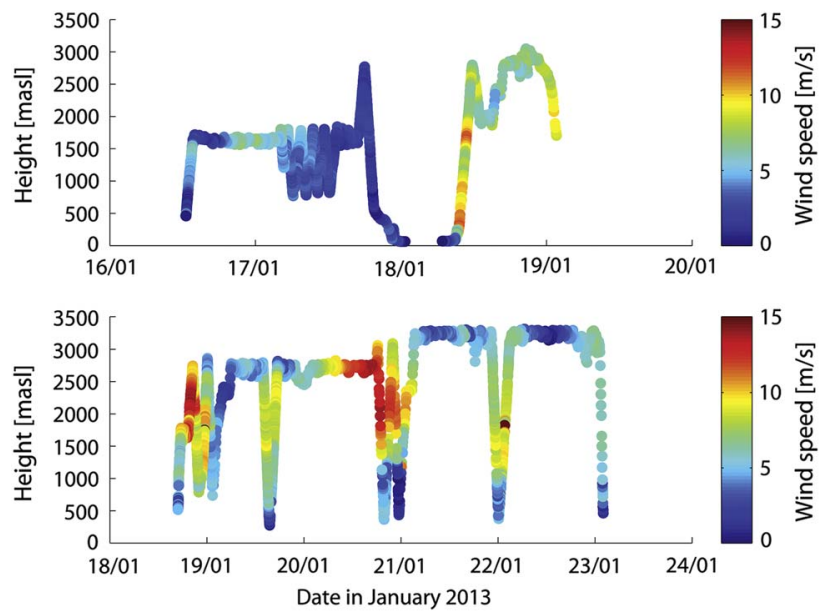

Fig. 3. Height profiles of Alpha (top) and Bravo (bottom), colour code is for wind speed $\left(\mathrm{m} \mathrm{s}^{-1}\right)$. Note that the time axis is shifted between the panels. 

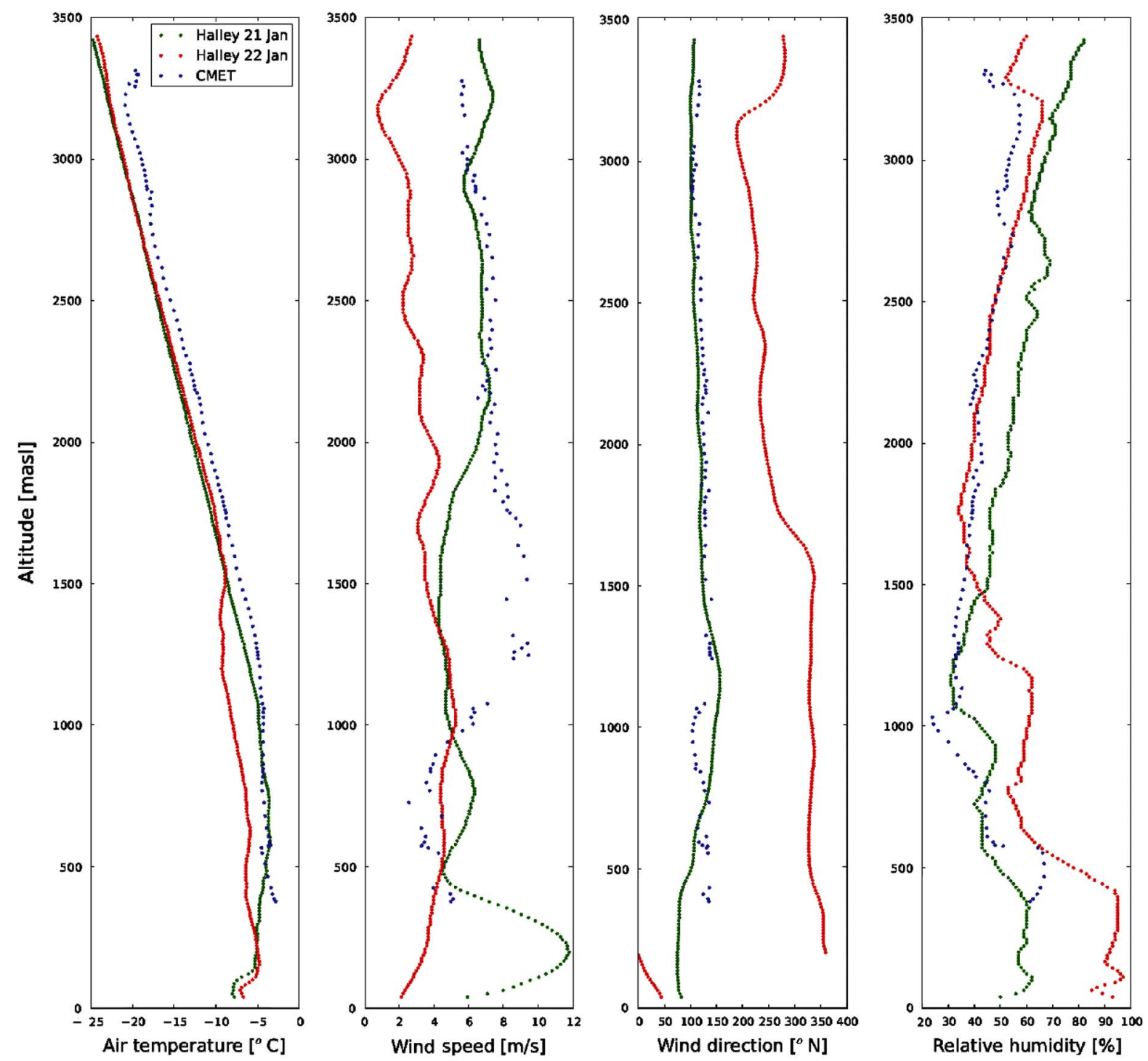

Fig. 4. Halley radiosonde profiles on 21 and 22 January 2013 at $12 \mathrm{~h} 00$ UTC compared to nearby Bravo profiles on 22 January at 00h00 UTC.

Further east there was cyclonic activity centred c. $400 \mathrm{~km}$ off the Princess Astrid Coast on 19-21 January. Figure 2 shows the trajectories of the two CMET balloons. Alpha drifted north-east, until it turned westward over the ice shelf and continued over the Weddell Sea. Winds carried Bravo first to the south-west, but then it returned to Aboa along almost the same path. Then Bravo's trajectory showed a counter-clockwise semicircle over the Weddell Sea. The radius of the circle was $c .250 \mathrm{~km}$, indicating a mesoscale anticyclone. Close to the end of the semicircle, Bravo passed Halley and continued over the continent on the Caird Coast. Then Bravo turned north-west and winds carried it over the Weddell Sea, where it dropped. The horizontal distances covered were $835 \mathrm{~km}$ for Alpha and $1989 \mathrm{~km}$ for Bravo. Figure 3 shows the altitude profiles of the two balloons. Alpha carried out multiple shallow soundings between 750 and $1750 \mathrm{~m}$ a.s.l. on day 2 of the flight, while Bravo carried out several deeper soundings between 300 and $3200 \mathrm{~m}$ a.s.l., particularly on days 3 and 4 .

Figure 4 compares the profiles of $\mathrm{T}$, ws, wd and $\mathrm{RH}$ from the CMET balloons and the Halley radiosondes on 21 and 22 January 2013. The radiosonde profiles were taken $c .12$ hours before and after the CMET balloon descent profile. The T measurements compare reasonably well, although with a slight warm offset.

Since the CMET balloons are moving in three dimensions with time, it is not appropriate to only compare them with vertical model profiles. Instead a four-dimensional approach was used, where each observation from the CMET balloons was compared 
a

WRF vs Ballon, AE Atmospheric pressure [hPa]

Absolute error $\bullet-$

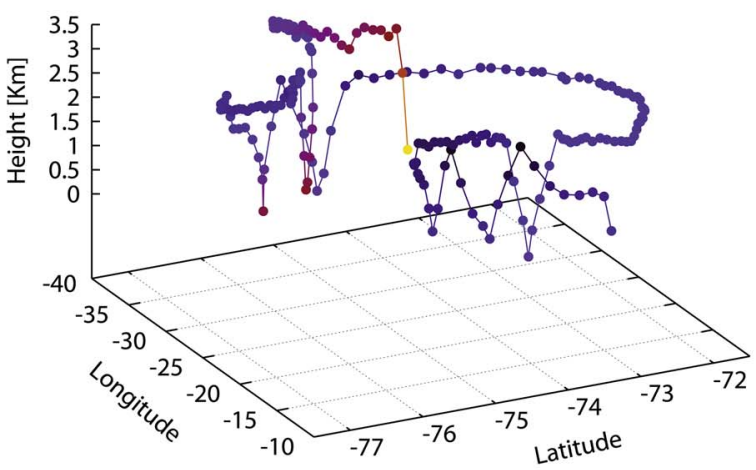

C

WRF vs Ballon, AE Air temperature [K]

Absolute error $\bullet-$

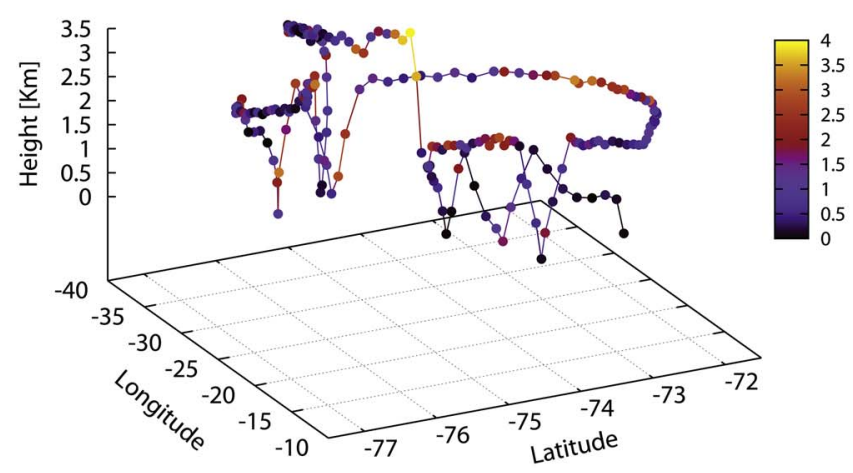

b

WRF vs Ballon, AE Wind speed [m/s]

Absolute error $\bullet-$

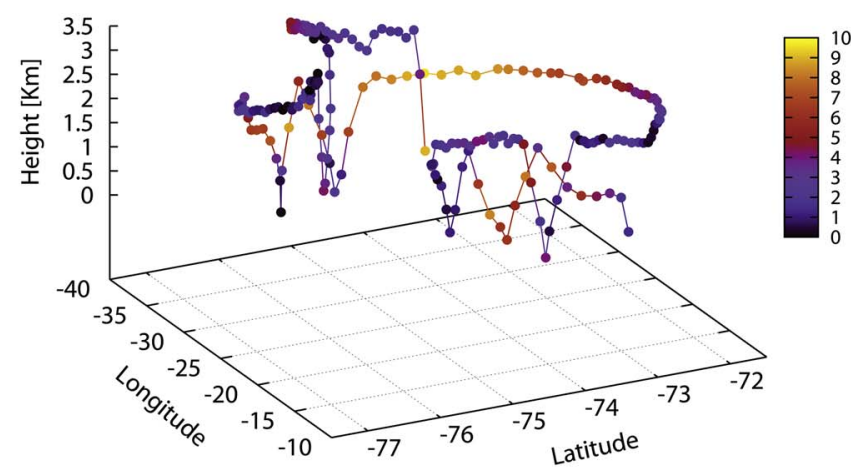

d

WRF vs Ballon, AE Relative humidity [\%]

Absolute error $\bullet-$

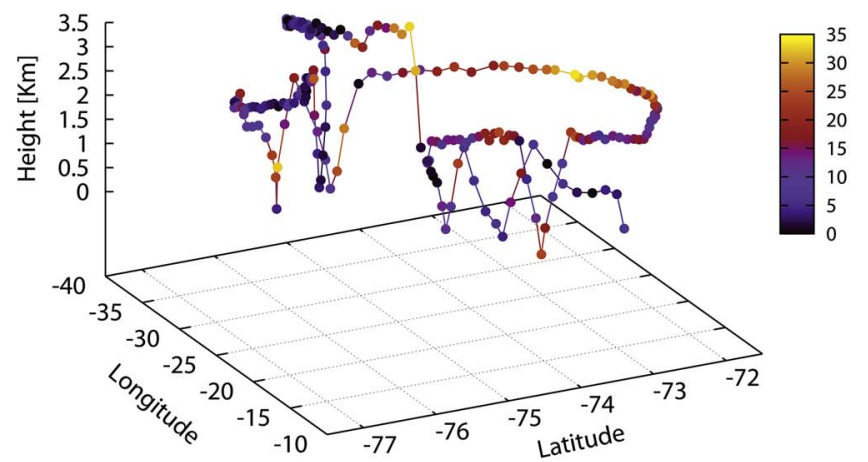

Fig. 5. 4-D comparison of controlled meteorological (CMET) balloon observations and weather research and forecasting (WRF) model output for the nearest grid point for each model time step (30 min). Output is shown for a. air pressure, b. wind speed, c. air temperature and $\mathbf{d}$. relative humidity.

with the nearest model grid point in time and space. Figure 5 shows the mean absolute errors (MAE) for $\mathrm{P}$, ws, $\mathrm{T}$ and $\mathrm{RH}$ from the Bravo flight (also summarized in Table II for Alpha and Bravo). These results indicate that the statistical model performance is independent of the choice of turbulence scheme. Comparing Figs 2 and 5 we see that the largest MAE in ws, T and RH occur when

Table II. Comparison of weather research and forecasting (WRF) model output and controlled meteorological (CMET) balloon observations for relative humidity $(\mathrm{RH})$, air temperature $(\mathrm{T})$, dew point temperature (Td), wind speed (ws) and air pressure (P). The mean absolute errors are given for WRF outputs applying the Yonsei University (YSU) and the Mellor-Yamada (MYJ) turbulence schemes.

\begin{tabular}{cccccc}
\hline & RH $(\%)$ & $\mathrm{T}(\mathrm{K})$ & $\mathrm{Td}(\mathrm{K})$ & ws $\left(\mathrm{m} \mathrm{s}^{-1}\right)$ & $\mathrm{P}(\mathrm{hPa})$ \\
\hline Alpha & & & & & \\
YSU & 15.9 & 1.5 & 6.2 & 2.1 & 9.1 \\
MYJ & 15.0 & 1.5 & 5.9 & 2.4 & 9.2 \\
Bravo & & & & & \\
YSU & 11.6 & 1.0 & 3.1 & 3.1 & 8.2 \\
MYJ & 12.1 & 1.1 & 3.3 & 3.1 & 8.3 \\
\hline
\end{tabular}

Bravo is cruising westward at c. $2500 \mathrm{~m}$ a.s.l. over the Weddell Sea on 20 January.

\section{Discussion and conclusions}

The most interesting feature detected by the CMET balloons was the mesoscale anticyclone over the Weddell Sea and the coastal zone. Mesoscale anticyclones are common in the ocean (e.g. Sabu et al. 2015) but much less in the atmosphere. The cases reported include the following. Blamey \& Reason (2009) detected an offshore mesoscale anticyclone at 800 $700 \mathrm{hPa}$ levels along the east coast of South Africa, and concluded via model experiments that coastal orography played an important role in its generation. Nishikawa et al. (2014) observed a mesoscale anticyclone over the Kuril Islands between the North Pacific and the Sea of Okhotsk. They concluded that it was generated by an extremely cold spot in the sea surface temperature. Mesoscale anticyclones have also occurred in Antarctic coastal regions but have received very little attention, as mesoscale cyclones have been more of a focus (Heinemann \& Klein 2003). 


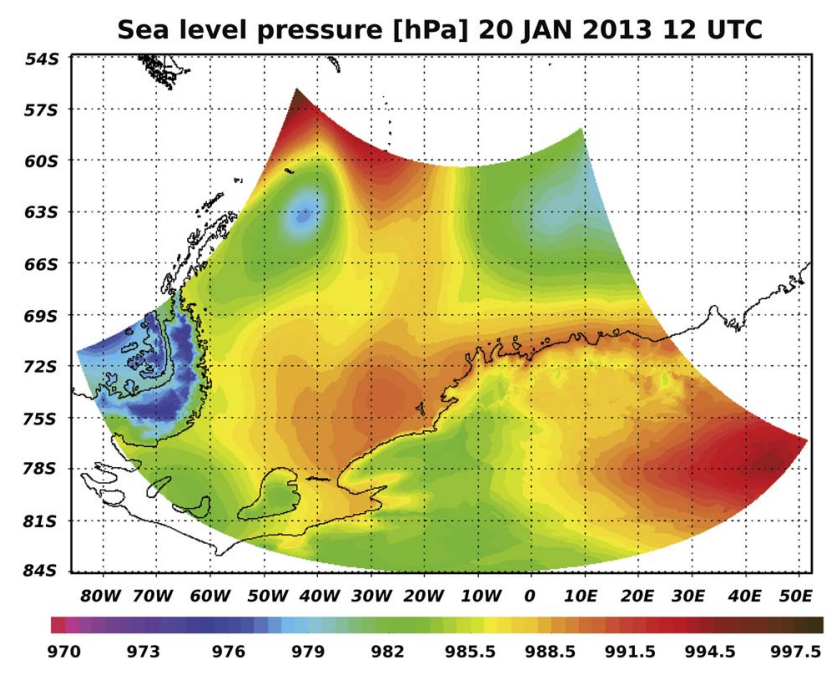

Fig. 6. Weather research and forecasting (WRF) sea level pressure in the inner $(3 \mathrm{~km})$ domain on 20 January 2013 at $12 \mathrm{~h} 00$ UTC.

In our case, the mesoscale anticyclone was reproduced by the WRF experiment (Fig. 6), but it was less intense than the actual observations. The modelled ws was up to $10 \mathrm{~m} \mathrm{~s}^{-1}$ lower and the RH was $20-40 \%$ higher than the values observed by Bravo (Fig. 5). The low ws in the model suggests that the pressure gradient related to the anticyclone was not strong enough in the model. However, over the study period, the WRF results generally agreed with the CMET balloon observations (Fig. 5) and radiosonde soundings at Halley (Fig. 4). The WRF output was also compared to the Halley weather station observations (not shown), and the ws values were within 1-2 $\mathrm{m} \mathrm{s}^{-1}$. The WRF model generated mesoscale cyclones slightly north-north-west of Halley on 18-23 January (not shown), but these were not resolved by the ERA Interim analysis. The sudden change in Bravo's trajectory west of Halley and the consecutive counterclockwise drift (Fig. 2) suggests that there was indeed a mesoscale cyclone in the region. Furthermore, other loops and sudden turns in the trajectories of Alpha and Bravo suggest the presence of mesoscale flow features, but the timings and locations do not match with the WRF results.

According to Heinemann \& Klein (2003), challenges in modelling mesoscale processes in the Antarctic coastal zone include parameterization of subgrid-scale physical processes, representation of the coastal orography and the inaccuracy of initial conditions. More recently, Zhang et al. (2015) addressed the problems in modelling the wind field over Antarctic coastal orography. All of these modelling challenges were present in our study. In addition, during the study period the sea ice coverage in the Weddell Sea was more extensive than average, with the ice edge c. 200-300 km further north (Fig. 2), which may have influenced cyclogenesis in the region. The anomalous sea ice cover was not well represented in the
GFS analysis used for the boundary conditions in the WRF model, which may have contributed to the differences in the observed and simulated cyclones.

To overcome the modelling problems more observations are needed for i) better identification of the errors, ii) further development of the subgrid-scale physical parameterizations, and iii) data assimilation to operational models. The CMET balloons have a lot of potential to yield observations for these purposes. In addition, as CMET balloon data are Lagrangian (except when vertical profiles are measured by adjusting the buoyancy of the system), they are well suited for mass budget studies of the Antarctic atmosphere. The mass flux associated with katabatic winds is assumed to be significant even on a global scale (Dalu et al. 1993). The mass lost by the katabatic outflow must be replaced by subsidence over Antarctica (Van de Berg et al. 2007) which in turn is fed in the middle and upper troposphere by convergence of air into a cyclonic vortex above Antarctica (Starr \& Vedder 1989, King \& Turner 1997). A larger number of CMET balloons could yield valuable information on these processes, or at least contribute to the evaluation of atmospheric reanalyses and model products.

In the future, a suite of CMET balloons could be launched with a strategy of having some long-duration CMET flights to follow air masses at constant altitude, and for other CMETs to undertake repeated soundingson-command to profile the atmosphere at specific times and locations of interest. Future development plans for the balloons include adding a drag string or proximity sensor so that soundings can reliably descend to within a few metres of the surface without damaging the sensor payload. The potential ability to conduct soundings in remote and otherwise inaccessible regions (such as crevasse areas) at low cost is rather unique to CMET balloons. Some UAVs may be capable of such measurements, but their operation requires significantly more personnel time, making long-term or repeated measurements less feasible. Repeated CMET soundings, into katabatic winds for example, could improve meteorological model performance in Antarctica yielding better forecasts and simulations of mass balance of the Antarctic ice sheet. Furthermore, the lifetime of the CMETs can almost certainly be increased (to 20 days or more) by using better balloon films or supplemental ballast. The dry climate in Antarctica is optimal for lightweight airborne sensors, and the problem of icing that is common to cold regions is avoided here. In addition to being able to carry out controlled soundings, the CMET balloons can collect long time-series at fixed altitudes (isentropic surfaces) in the free troposphere. This could be valuable for model validation and for tracking air masses, for example during atmospheric chemistry studies (Voss et al. 2010). 


\section{Acknowledgements}

We thank Mika Kalakoski and Petri Heinonen from the Finnish Antarctic Research Programme (FINNARP) for launching the CMETs at the Aboa Station. The work was supported by the Academy of Finland (contract 263918) and the Scientific Committee on Antarctic Research Physical Sciences working group and the Research Council of Norway (contract 211390 and 221418). Radiosonde data were provided by Mr Steve Colwell of BAS, ERA Interim data were obtained from the European Centre for MediumRange Weather Forecasts, while boundary forcing data for the WRF simulations were obtained from the Global Forecast System produced by the US National Centers for Environmental Prediction.

\section{Author contribution statement}

Dr Lars R. Hole was involved in the field measurements and was primarily responsible for data analysis and writing the manuscript. Mr Alexis Bello was responsible for WRF simulations and analysis, comparisons with observations and figure preparation. Dr Tjarda Roberts and Dr Timo Vihma were involved in discussing the results and putting them into context. Dr Paul Voss was responsible for field measurements and analysis of observations.

\section{References}

Andreas, E.L. 2002. Parameterizing scalar transfer over snow and ice: a review. Journal of Hydrometeorology, 3, 417-432.

Barbaro, E., Zangrando, R., Vecchiato, M., Piazza, R., Cairns, W.R.L., Capodaglio, G., Barbante, C. \& Gambaro, A. 2015. Free amino acids in Antarctic aerosol: potential markers for the evolution and fate of marine aerosol. Atmospheric Chemistry and Physics, 15, 10.5194/ acp-15-5457-2015.

Blamey, R.C. \& Reason, C.J.C. 2009. Numerical simulation of a mesoscale convective system over the east coast of South Africa. Tellus - Dynamic Meteorology and Oceanography, 61A, 17-34.

Bromwich, D.H., Monaghan, A.J., Manning, K.W. \& Powers, J.G. 2005. Real-time forecasting for the Antarctic: an evaluation of the Antarctic Mesoscale Prediction System (AMPS). Monthly Weather Review, 133, 579-603.

Bromwich, D.H., Nicolas, J.P., Monaghan, A.J., Lazzara, M.A., Keller, L.M., Weidner, G.A. \& Wilson, A.B. 2014. Central West Antarctica among the most rapidly warming regions on Earth. Nature Geoscience, 6, 139-145. Corrigendum: Nature Geoscience, $7,76$.

CAssano, J.J. 2014. Observations of atmospheric boundary layer temperature profiles with a small unmanned aerial vehicle. Antarctic Science, 26, 205-213.

Chen, F. \& Dudhia, J. 2001. Coupling an advanced land surfacehydrology model with the Penn State-NCAR MM5 modeling system. Part I: model implementation and sensitivity. Monthly Weather Review, 129, 569-585.

Dalu, G.A., Baldi, M., Moran, M.D., Nardone, C. \& Sbano, L. 1993. Climatic atmospheric outflow at the rim of the Antarctic continent. Journal Geophysical Research - Atmospheres, 98, 12 955-12960.

Durre, I., Vose, R.S. \& Wuertz, D.B. 2006. Overview of the Integrated Global Radiosonde Archive. Journal of Climate, 19, 53-68.
Handorf, D., Foken, T. \& Kottmeier, C. 1999. The stable atmospheric boundary layer over an Antarctic ice sheet. Boundary-Layer Meteorology, 91, 165-189.

Heinemann, G. \& Klein, T. 2003. Simulations of topographically forced mesocyclones in the Weddell Sea and the Ross Sea region of Antarctica. Monthly Weather Review, 131, 302-316.

Hong, S.-Y., Dudhia, J. \& Chen, S.-H. 2004. A revised approach to ice microphysical processes for the bulk parameterization of clouds and precipitation. Monthly Weather Review, 132, 103-120.

Iacono, M.J., Delamere, J.S., Mlawer, E.J., Shephard, M.W., Clough, S.A. \& Collins, W.D. 2008. Radiative forcing by longlived greenhouse gases: calculations with the AER radiative transfer models. Journal Geophysical Research - Atmospheres, 113, 10.1029/2008JD009944.

Jonassen, M.O., Tisler, P., Altstädter, B., Scholtz, A., Vihma, T., Lampert, A., König-Langlo, G. \& LüpKes, C. 2015. Application of remotely piloted aircraft systems in observing the atmospheric boundary layer over Antarctic sea ice in winter. Polar Research, 34, 10.3402/polar.v34.25651.

Kain, J.S., Coniglio, M.C., Correia, J., Clark, A.J., Marsh, P.T., Ziegler, C.L., Lakshmanan, V., Miller, S.D., Dembek, S.R., Weiss, S.J., Kong, F.Y., Xue, M., Sobash, R.A., Dean, A.R., JIRAK, I.L. \& MeLICK, C.J. 2013. A feasibility study for probabilistic convection initiation forecasts based on explicit numerical guidance. Bulletin of the American Meteorological Society, 94, $1213-1225$.

KIng, J.C. \& Turner, W.M. 1997. Antarctic meteorology and climatology. New York, NY: Cambridge University Press, 409 pp.

KnUth, S.L. \& Cassano, J.J. 2014. Estimating sensible and latent heat fluxes using the integral method from in situ aircraft measurements. Journal of Atmospheric and Oceanic Technology, 31, 1964-1981.

Lazzara, M.A., Weidner, G.A., Keller, L.M., Thom, J.E. \& Cassano, J.J. 2012. Antarctic Automatic Weather Station Program: 30 years of polar observation. Bulletin of the American Meteorological Society, 93, 1519-1537.

Nishikawa, H., Tachibana, Y. \& Udagawa, Y. 2014. Radiosonde observational evidence of the impact of an extremely cold SST spot on a mesoscale anticyclone. Journal of Geophysical Research Atmospheres, 119, 10.1002/2014JD021538.

Nygård, T., Valkonen, T. \& Vihma, T. 2013. Antarctic lowtropospheric humidity inversions: 10-yr climatology. Journal of Climate, 26, 10.1175/JCLI-D-12-00446.1.

PirazzinI, R. 2004. Surface albedo measurements over Antarctic sites in summer. Journal Geophysical Research - Atmospheres, 109, 10.1029/2004JD004617.

Powers, J.G., Manning, K.W., Bromwich, D.H., Cassano, J.J. \& CAYette, A.M. 2012. A decade of Antarctic science support through AMPS. Bulletin of the American Meteorological Society, 93, 1699-1712.

Roberts, T.J., Dutsch, M., Hole, L.R. \& Voss, P.B. 2015. Controlled meteorological (CMET) balloon profiling of the Arctic atmospheric boundary layer around Spitsbergen compared to a mesoscale model. Atmospheric Chemistry and Physics Discussions, 15, 10.5194/acpd-1527539-2015.

Sabu, P., George, J.V., Anilkumar, N., Chacko, R., Valsala, V. \& ACHUTHANKUTTY, C.T. 2015. Observations of watermass modification by mesoscale eddies in the subtropical frontal region of the Indian Ocean sector of Southern Ocean. Deep-Sea Research II - Topical Studies in Oceanography, 118, 10.1016/j.dsr2.2015.04.010.

Skamarock, W.C., Klemp, J.B., Dudhia, J., Gill, D.O., Barker, D.M., Duda, M.G., Huang, X,-Y., Wang, W. \& Powers, J.G. 2008. $A$ description of the advanced research WRF version 3. NCAR technical note TN-475+STR. Boulder, CO: National Center for Atmospheric Research, 113 pp. 
Starr, W.L. \& Vedder, J.F. 1989. Measurements of ozone in the Antarctic atmosphere during August and September 1987. Journal of Geophysical Research - Atmospheres, 94, 11 449-11 463.

Stenmark, A., Hole, L.R., Voss, P., Reuder, J. \& Jonassen, M.O. 2014. The influence of nunataks on atmospheric boundary layer convection during summer in Dronning Maud Land, Antarctica. Journal Geophysical Research - Atmospheres, 119, 10.1002/2013JD021287.

Tastula, E.-M. \& Vinma, T. 2011. WRF model experiments on the Antarctic atmosphere in winter. Monthly Weather Review, 139, 10.1175/2010MWR3478.1.

Tastula, E.-M., Vihma, T. \& Andreas, E.L. 2012. Evaluation of polar WRF from modeling the atmospheric boundary layer over Antarctic sea ice in autumn and winter. Monthly Weather Review, 140, 3919-3935.

Turner, J. \& Pendlebury, S.F., eds. 2004. The international Antarctic weather forecasting handbook. Cambridge: British Antarctic Survey, $663 \mathrm{pp}$.

Van de Berg, W.J., van den Broeke, M.R. \& van Meijgaard, E. 2007. Heat budget of the East Antarctic lower atmosphere derived from a regional atmospheric climate model. Journal of Geophysical Research - Atmospheres, 112, 10.1029/2007JD008613.

Van den Broeke, M.R., Reijmer, C. \& van de Wal, R. 2004. Surface radiation balance in Antarctica as measured with automatic weather stations. Journal Geophysical Research - Atmospheres, 109, 10.1029/ 2003JD004394.
Voss, P.B., Hole, L.R., Helbling, E.F. \& Roberts, T.J. 2013. Continuous in-situ soundings in the Arctic boundary layer: a new atmospheric measurement technique using controlled meteorological balloons. Journal of Intelligent \& Robotic Systems, 70, 609-617.

Voss, P.B., Zaveri, R.A., Flocke, F.M., Mao, H., Hartley, T.P., DeAmicis, P., Deonandan, I., Contreras-Jimenez, G., MartinezAntonio, O., Estrada, M.F., Greenberg, D., Campos, T.L., Weinheimer, A.J., Knapp, D.J., MontzKa, D.D., Crounse, J.D., Wennberg, P.O., Apel, E., Madronich, S. \& de Foy, B. 2010. Longrange pollution transport during the MILAGRO-2006 campaign: a case study of a major Mexico City outflow event using free-floating altitude-controlled balloons. Atmospheric Chemistry and Physics, 10, 7137-7159.

Walden, V.P., Warren, S.G. \& Murcray, F.J. 1998. Measurements of the downward longwave radiation spectrum over the Antarctic Plateau and comparisons with a line-by-line radiative transfer model for clear skies. Journal Geophysical Research - Atmospheres, 103, 10.1029/97JD02433.

Zhang, Z., Vihma, T., Stössel, A. \& Uotila, P. 2015. The role of wind forcing from operational analyses for the model representation of Antarctic coastal sea ice. Ocean Modelling, 94, 10.1016/j.ocemod. 2015.07.019. 